\title{
The changing face of palliative care
}

\begin{abstract}
The face of palliative care has changed considerably in the past four decades. The increased consumption of opioids did not fulfil the promise of freedom from pain. The reason for this may be that cancer patients live longer and suffer from different types of pain than before. Increasingly, patients suffer because of treatment-induced pain and pain due to degeneration and deterioration. Different strategies for coping with pain are now needed in comparison with four decades ago.
\end{abstract}

Key words: palliative care, epidemiology of cancer pain, cancer pain, oncology, morphine, opioids, opioid-resistant pain, opioid-induced hyperlagesia, opioid-induced hypogonadism

Adv. Pall. Med. 2011; 10, 3-4: 85-88

\section{Introduction}

The credit for the development of palliative care and later palliative medicine should be given to Dame Cicely Saunders, who established the first modern hospice in South London in 1967 [1]. This institution and many that followed was meant to provide care for those with progressive and incurable diseases. The care was provided not only to the patients, but also to their families. Although the initial focus was on dying patients with cancer, palliative care evolved rapidly and hospices and palliative care units nowadays provide care whenever it is needed, independent of the type and advancement of diseases [1].

Important issues brought up by Dame Cicely and placed on the world agenda were the wider availability of opioids, especially morphine, and pain under-treatment. Morphine was coined as a gold standard and at that time it was believed that there was a linear relationship between the dose of morphine and its analgesic effect. Not infrequently patients were treated with mega doses of opioids, something we do not now encounter every day [2]. In the focus on under-treatment, there was also a hid- den promise: once we are able to treat everybody who needs it with morphine, the problem of pain, especially in cancer, can be solved.

Much has been done by Dame Cicely and her followers, among them Balfour Mount, Robert Twycross, Geoff Hanks, Vittorio Ventafridda and many others. The teaching of palliative care and pain treatment has become the norm in many universities. Much later than that, ongoing, extremely relevant research emerged on all continents. The numbers of hospices and palliative care units increased to thousands and the specialty of Palliative Medicine emerged in several countries.

At that time, doctors were clearly recognizing that some pains would not respond to morphine or may respond initially but then become resistant to the drug at a later stage. It was thought that most of these aberrant pains were of neuropathic origin and that the addition of co-analgesics would solve the problem. In 1985 a simple scheme, the so-called WHO analgesic ladder, was launched [3]. This scheme was developed to fight cancer pain but became the standard in many other fields. The three steps, some of them still disputed $[4,5]$,

Address for correspondence: Zbigniew Zylicz, MD, PhD

Hildegard Hospiz

St. Alban Ring 151, 4020 Basel, Schweiz

e-mail: ben.zylicz@hildegard-hospiz.ch

(7M Advances in Palliative Medicine 2011, 10, 85-88

Copyright ( $) 2011$ Via Medica, ISSN 1898-3863 
revolutionized the pain treatment in cancer. Good pain control became a human right and politicians, together with doctors and nurses, struggled side by side to achieve their goals: to build more hospices, have them financed and break through the myths and prejudices about morphine and other opioids. Opioid consumption became a parameter of a country's development in palliative care and a surrogate for its quality $[6,7]$.

The main idea of the WHO ladder was to "keep it simple". However, the scheme simplified so much that the idea emerged that ALL pains in cancer could be treated with morphine \pm co-analgesics $[8,9]$. As a result of this, doctors did not bother to investigate and describe pain well because the treatment was always the same.

In this article we shall reflect on what happened next and where we are now concerning pain in cancer. We may also look a little way into the future.

\section{Do cancer patients live longer?}

In the past 40 years we have been through a true revolution in oncology. Although the numbers of patients cured from cancer have increased slowly but steadily, the kinds of cancer that can be cured have not changed much $[10,11]$. However, the patients with the most common cancers do live longer and in many cases cancer became a chronic disease with survival rates superior to those of chronic kidney or liver diseases [11].

\section{Does living longer means suffering longer pain?}

In a recent meta-analysis of 154 trials it was found that approximately half the patients with cancer of all stages suffer from pain [12]. When the cancer is more advanced, the numbers are approximately $10 \%$ higher. New in this analysis was that approximately one third of patients under active treatment suffer from pain and also that there is a large group (33\%) of cancer survivors who suffer from pain [12].

What does this mean? First of all, it means that the numbers of patients with advanced cancer and pain have not changed in the past 40 years. Modern oncology prolongs patients' survival, but does not cure the pain; at least, not for ever and not when the tumour has become far advanced. The patients after treatment may enjoy longer periods without pain but may also suffer longer periods with discomfort and pain later.

\section{Pain treatment in a patient with a short prognosis is easier}

Forty years ago, the time of great enthusiasm around opioid use, patients were treated with opioids for shorter periods of time simply because they were dying much earlier. Phenomena such as opioid tolerance, drug addiction and loss of analgesic potential were seldom observed. They were also, for political reasons, found to be unimportant and insignificant. We needed to convince prescribers not to be afraid of these phenomena. On the other hand, some types of pain, especially neuropathic pain were also seen less often. After damage to the nerve, it takes a couple of months to develop a full picture of neuropathic pain $[13,14]$. It is thus conceivable that 40 years ago we encountered neuropathic pain less often as patients' survival was much shorter. However, this is not yet confirmed by epidemiologists.

\section{What do cancer survivors tell us?}

A new group, which remained unseen for a long time, was that of the cancer survivors. This group is becoming larger and larger. In one third of them, any good effect of treatment was exchanged for pain as a result of healthy tissue damage due to aggressive treatment [12]. Modern oncology treatment may irreversibly damage skin, nerves, bones and other tissues. The pains emerging from the treatment cannot be classified as "cancer pain" (as the cancer is gone) and will frequently not respond to opioids. It is conceivable, but still not documented by epidemiologists, that patients who are not cured from cancer are, besides the damage due to the tumour growth, also suffering the same damage to tissues due to the treatment.

\section{"Cancer pain" or "pain in cancer"?}

Taking these data altogether, one could think that the qualities of pain encountered in patients with cancer nowadays may be different from forty years ago. The percentage of patients suffering opioid-resistant pains could be higher than previously. It is thus better not to call all pains "cancer pains" but to differentiate them for each patient and treat them separately. It would also be well to remember that the simple World Health Organization (WHO) analgesic ladder was mainly designed for generic "cancer pain" and most of the "cancer pain" was considered sensitive to opioids. 


\section{Opioid consumption}

As a consequence of the efforts of pioneers, opioid consumption rose dramatically over the past 40 years $[15,16]$. Sometimes tenfold or more. While there are still many countries which are underusing opioids, frequently for cultural reasons, we are now in the rich West confronted with countries whose populations consume very high amounts of opioids. In these countries, it is not under-treatment but over-treatment and opioid toxicity which have become a problem.

\section{Progress in pain control?}

In fact, most progress in pain control has been made in the area of "true cancer pain", which means pains directly related to tumour growth (compression or infiltration by tumour). The most successful technologies in treating this kind of pain have been radio-, hormone- and chemotherapy. Opioids are only adjunctive to these techniques and cannot deal with the pain alone. By treating the tumours aggressively we decrease the likelihood of tumour-related pain but increase the likelihood of pain due to tissue damage and degeneration. These latter are less prone to responding to opioids.

Thus, in thinking of "cancer pain" which needs opioids and is usually "opioid sensitive", we may overdose some patients and treat them with toxic doses. These patients may also be so kind to us as to die earlier due to opioids before larger problems appear.

\section{New phenomena related to opioid toxicity}

\section{Cognitive impairment}

New phenomena, previously unknown or not considered important, have emerged in the last decade. The first of these is cognitive failure. Opioids, while effective against many pains, may also induce progressive cognitive impairment [17-19]. Occasionally, this may progress to delirium and psychosis. For a long time it was thought fair to control somebody's pain at the cost of (slight) cognitive impairment. However, when treatment with opioids needed to be extensive, cognitive impairment became a problem, compromising patients' quality of life. New technologies, sometimes invasive and risky, emerged for treating pain without or with lower doses of opioids. These techniques were, however, discouraged because of their invasive- ness and difficulty in accessing them but mainly because of the risk of pain exacerbation instead of its annihilation. At the moment cognitive impairment is seen as a symptom of neurotoxicity and several approaches to it have been developed.

\section{Opioid-induced hyperalgesia (OIH)}

When opioids are administered for a longer time, patients may notice that their analgesic potency decreases and also that the quality of pain changes. This phenomenon may be more common than previously thought [20]. From the focal pain due to cancer growth clearly seen on the MRI, patients start to suffer from more generalized pain which is unexplainable with the advent of modern diagnostic techniques. It is highly probable that some patients are particularly sensitive to these phenomena, which in general depend on pain facilitation in the spinal cord $[21,22]$. In these patients OIH may emerge rapidly within hours or days after commencement of treatment. However, most vulnerable is the population of (former) drug addicts, who frequently develop $\mathrm{OIH}$ and may suffer severe pain when later having cancer.Different opioids may influence $\mathrm{OIH}$ in a different manner. Some opioids are potent OIH inducers, others not. Thus, opioid switching can help for a while [23].

\section{Opioid-induced hypogonadism}

Another phenomenon, known about for more than 100 years, is opioid-induced hypogonadism [24]. Morphine and most other opioids (except buprenorphine) [25-27] inhibit the hypophyseal excretion of gonadotropic hormones. When the gonads and adrenals are not stimulated by gonadotropins, they do not produce sex hormones and we are then talking about hypogonadism. The main issue in hypogonadism is that the patients feel fatigued, have increased sensitivity to pain, but also suffer from a number of degenerative disorders, such as osteoporosis and muscle and skin atrophy, all of which can be the source of new pain [28-31]. Hypogonadism may also be correlated with adrenal insufficiency and may exacerbate it. It has been estimated that over $80 \%$ of patients treated with opioids for a long time suffer because of hypogonadism [24]. Yet, this phenomenon was neglected in research for a long time. Again, patients lived too short a time to be bothered by this phenomenon. Hormone substitution, although cheap and possible, has not attracted much attention and we are left with a small number of case reports and anecdotes but no trials or evidence. 


\section{Conclusion}

The patient who is seeking our advice in the year 2011 is a different patient from four decades ago. Potentially, he will suffer from different kinds of pain and will show different sensitivity to opioids. He may have a chance of being treated with high doses of opioids and may suffer from the long-term adverse effects of opioids, which are still poorly researched and do not attract much attention from the oncology community. Oncology has taken a major step forward but has left palliative care somewhat behind. Palliative care should recognize this and stop chasing ideals dating from four decades ago, and instead formulate new targets and develop new treatments. Recognizing each pain separately and finding the appropriate treatment for each of them is the key to success. Be careful, however. If we do not keep it simple, as advised before, we may end up in a complicated mess and make more (sometimes fatal) mistakes than before.

The key advice for the doctors and nurses involved in the care of patients with cancer is that there is no "cancer pain"; only "pain in cancer".

\section{References}

1. Saunders $C$. The evolution of palliative care. Pharos Alpha Omega Alpha Honor Med. Soc. 2003; 66: 4-7.

2. Smith K.J., Miller A.J., McKellar J., Court M. Morphine at gramme doses: kinetics, dynamics and clinical need. Postgrad. Med. J. 1991; 67 (Suppl. 2): S55-S59.

3. Ventafridda V., Saita L., Ripamonti C., De Conno F. WHO guidelines for the use of analgesics in cancer pain. Int. J. Tissue React. 1985; 7: 93-96.

4. Jadad A.R., Browman G.P. The WHO analgesic ladder for cancer pain management. Stepping up the quality of its evaluation. JAMA 1995; 274: 1870-1873.

5. Maltoni M., Scarpi E., Modonesi C. et al. A validation study of the WHO analgesic ladder: a two-step vs three-step strategy. Support Care Cancer 2005; 13: 888-894.

6. Clausen T.G. International opioid consumption. Acta Anaesthesiol. Scand. 1997; 41: 162-165.

7. De Conno F., Ripamonti C., Brunelli C. Opioid purchases and expenditure in nine western European countries: "are we killing off morphine?". Palliat. Med. 2005; 19: 179-184.

8. Christo PJ, Mazloomdoost D. Cancer pain and analgesia. Ann. N.Y. Acad. Sci. 2008; 1138: 278-298.

9. Mishra S., Bhatnagar S., Gupta D., Nirwani Goyal G., Jain R., Chauhan $\mathrm{H}$. Management of neuropathic cancer pain following WHO analgesic ladder: a prospective study. Am. J. Hosp. Palliat. Care 2008; 25: 447-451.

10. Francisci S., Capocaccia R., Grande E. et al. The cure of cancer: a European perspective. Eur. J. Cancer 2009; 45: 1067-1079.

11. Rosso S., De Angelis R., Ciccolallo L. et al. Multiple tumours in survival estimates. Eur. J. Cancer 2009; 45: 1080-1094.

12. van den Beuken-van Everdingen M.H., de Rijke J.M., Kessels A.G., Schouten H.C., van Kleef M., Patijn J. Preva- lence of pain in patients with cancer: a systematic review of the past 40 years. Ann. Oncol. 2007; 18: 1437-1449.

13. Martin L.A., Hagen N.A. Neuropathic pain in cancer patients: mechanisms, syndromes, and clinical controversies. J. Pain Symptom Manage. 1997; 14: 99-117.

14. Baron R. Peripheral neuropathic pain: from mechanisms to symptoms. Clin. J. Pain 2000; 16: S12-S20.

15. Seya M.J., Gelders S.F., Achara O.U., Milani B., Scholten W.K. A first comparison between the consumption of and the need for opioid analgesics at country, regional, and global levels. J. Pain Pall. Care Pharmacother. 2011; 25: 6-18.

16. Ponizovsky A.M., Marom E., Zeldin A., Cherny N.I. Trends in opioid analgesics consumption, Israel 2000-2008. Eur. J. Clin. Pharmacol. 2011; 67: 165-168.

17. Kurita G.P., de Mattos Pimenta C.A. Cognitive impairment in cancer pain patients receiving opioids: a pilot study. Cancer Nursing 2008; 31: 49-57.

18. Vella-Brincat J., Macleod A.D. Adverse effects of opioids on the central nervous systems of palliative care patients. J. Pain Palliat. Care Pharmacother. 2007; 21: 15-25.

19. Ersek M., Cherrier M.M., Overman S.S., Irving G.A. The cognitive effects of opioids. Pain Manage. Nurs. [official journal of the American Society of Pain Management Nurses] 2004; 5: 75-93.

20. Zylicz Z., Twycross R. Opioid-induced hyperalgesia may be more frequent than previously thought. J. Clin. Oncol. 2008; 26: 1564.

21. Silverman S.M. Opioid induced hyperalgesia: clinical implications for the pain practitioner. Pain Physician 2009; 12: 679-684.

22. Hay J.L., White J.M., Bochner F., Somogyi A.A., Semple T.J., Rounsefell B. Hyperalgesia in opioid-managed chronic pain and opioid-dependent patients. J. Pain 2009; 10 : 316-322.

23. Fine P.G. Opioid insights:opioid-induced hyperalgesia and opioid rotation. J. Pain Palliat. Care Pharmacother. 2004; 18: 75-79.

24. Reddy R.G., Aung T., Karavitaki N., Wass J.A. Opioid induced hypogonadism. BMJ 2010; 341: c4462.

25. Bliesener N., Albrecht S., Schwager A., Weckbecker K., Lichtermann D., Klingmuller D. Plasma testosterone and sexual function in men receiving buprenorphine maintenance for opioid dependence. J. Clin. Endocrinol. Metab. 2005; 90: 203-206.

26. Ceccarelli I., De Padova A.M., Fiorenzani P., Massafra C., Aloisi A.M. Single opioid administration modifies gonadal steroids in both the CNS and plasma of male rats. Neuroscience 2006; 140: 929-937.

27. Hallinan R., Byrne A., Agho K., McMahon C.G., Tynan P., Attia J. Hypogonadism in men receiving methadone and buprenorphine maintenance treatment. Int. J. Androl. 2009; 32: 131-139.

28. Miner M.M., Sadovsky R. Evolving issues in male hypogonadism: evaluation, management, and related comorbidities. Cleve Clin. J. Med. 2007; 74 (Suppl 3): S38-S46.

29. Ozata M., Odabasi Z., Caglayan S., Beyhan Z., Vural O., Ozdemir C. Event-related brain potentials in male hypogonadism. J. Endocrinol. Invest. 1999; 22: 508-513.

30. Rajagopal A., Vassilopoulou-Sellin R., Palmer J.L., Kaur G., Bruera E. Hypogonadism and sexual dysfunction in male cancer survivors receiving chronic opioid therapy. J. Pain Symptom Manage. 2003; 26: 1055-1061.

31. Rajagopal A., Vassilopoulou-Sellin R., Palmer J.L., Kaur G., Bruera E. Symptomatic hypogonadism in male survivors of cancer with chronic exposure to opioids. Cancer 2004; 100: 851-858. 